\title{
APRECIAÇÃO DOS CUSTOS OCULTOS DO PROCESSO SUCROALCOOLEIRO EM UMA USINA DE ÁLCOOL NA PARAIBA
}

\section{APPRECIATION OF THE OCCULT COSTS OF PROCESS SUCROALCOOLEIRO IN AN ALCOHOL PLANT IN THE PARAIBA}

\author{
João Batista de Freitas ${ }^{1}$; Cosmo Severiano Filho ${ }^{2}$ \\ ${ }^{1}$ Universidade Federal da Paraíba - UFPB/DEP - João Pessoa - Brasil joaosousa@oi.com.br \\ ${ }^{2}$ Universidade Federal da Paraíba - UFPB/DEP - João Pessoa - Brasil cosmosf@ufpb.ct.br
}

\begin{abstract}
Resumo
Os avanços tecnológicos e as constantes mudanças que vêm ocorrendo no cenário da economia mundial conseqüentemente também refletem em necessidades de mudanças na contabilidade. Neste contexto, percebe-se que há uma necessidade de aprimorar os procedimentos contábeis para que venham contemplar a contabilização dos Custos Ocultos. O presente artigo trata de uma pesquisa que procurou identificar os Custos Ocultos presentes em uma Agroindústria "Destilaria de álcool". Ressalta-se que o fruto desta pesquisa é o embasamento cientifico e prático sobre o estudo dos Custos Ocultos. Inicialmente apresenta-se a contextualização e evolução da Contabilidade de Custos, culminando com a classificação e origem dos Custos Ocultos. Posteriormente são levantados os possíveis Custos Ocultos presentes na Agroindústria "Destilaria de álcool"
\end{abstract}

Palavras-chave: Custo Oculto, Custo e Contabilidade de Custos.

\section{Introdução}

A crescente mudança no cenário econômico impulsiona as organizações a adotarem diferenciadas estratégias a fim de se adequarem e sobreviverem no mercado. A sociedade vem presenciando mudanças no mundo, e uma delas é a forma pelo qual os empresários passaram a observar suas empresas, ou seja, por novos focos, não só como fonte, meio e processo da evolução da economia mundial, mas principalmente como um sistema que interage com vários custos, sejam ocultos ou não. Paralelo a isso se observa um crescimento em busca do aumento da produtividade e, conseqüentemente, um ganho maior no segmento de consumo.

Dessa forma, as empresas devem conhecimento de todos os custos, pois estes estão intimamente relacionados com a produção de itens. No entender de Megliorini (2001), os custos são os reflexos da empresa em atitudes, comportamentos, estruturas e modos de operar, e quanto mais 
estruturada for, melhores serão os resultados encontrados, e quanto menos informações estiverem disponíveis, ou se a qualidade dessas informações não for confiável, os resultados encontrados serão deficientes.

$\mathrm{Na}$ atualidade, a preocupação não é apenas com as formas de escrituração dos fatos contábeis, mas em identificar, mensurar e acumular os custos de um determinado produto, visando prover informações necessárias à tomada de decisão, avaliação dos estoques e apuração do resultado econômico, por meio do controle de custos e receitas e criar condições para acompanhar o desempenho empresarial.

A compreensão sobre a importância e valor dos intangíveis vem crescendo em decorrência da relevância do desempenho administrativo e operacional, bem como diretamente relacionado com as funções de planejamento, orçamento e controle.

O termo "Custo Oculto" pode ser definido como um gasto referente à atividade de produção, no qual sua principal característica é ser de difícil mensuração, ou seja, os custos ocultos não podem ser reconhecidos facilmente ou atribuídos a um determinado processo produtivo onde são gerados. Além disso, estes custos são numerosos e muito mais altos que o esperado pela maioria dos departamentos de contabilidade.

O segmento estudado é o agroindustrial e setor sucroalcooleiro, isso em função de sua importância no cenário econômico, pois o mesmo oferece uma alternativa de subsistência. Além do mais, absorve grande parte da mão-de-obra agrária oriunda de redutos familiares, assolados pelo alto índice de desestabilização, abertura econômica (globalização) e políticas governamentais recessivas.

A razão da escolha da indústria centra-se na importância do setor sucroalcooleiro no Brasil e na região Nordeste, "com destaque nas áreas de destilaria, processos de fabricação e análise do produto" e um dado muito importante, é que nos últimos dez anos, a produção de álcool cresceu $58 \%$.Partindo-se desse pressuposto, o presente trabalho tem como objetivo Identificar os elementos de custos ocultos em um processo do setor agroindustrial, especificamente o segmento sucroalcooleiro.

Para tanto, inicialmente é realizada uma breve revisão da literatura acerca da Contabilidade de Custos e a classificação dos custos, bem como os principais aspectos que delineiam teoricamente os Custos Ocultos. Em seguida, comenta-se a respeito da agroindústria onde foi realizada pesquisa, no intuito de situar o leitor acerca do contexto do estudo e menciona-se como foi efetuada a coleta de dados que resultou na identificação dos Custos Ocultos. Por último, são elencadas as considerações finais oriundas do estudo. 


\section{Metodologia}

A pesquisa foi realizada em uma agroindústria do setor de "destilaria de álcool", cujo foco principal é exclusivamente a fabricação de álcool. Tal especialização levou a Agroindústria a se destacar nas áreas de destilaria, processos de fabricação e análise do produto.

O estudo foi desenvolvido no escopo do processo de produção de álcool no período de novembro a dezembro de 2005. Sabe-se que o período de concentração de atividades nesta destinaria "período de safra", corresponde aos meses de agosto a fevereiro. Nos demais meses de "entre safra", ocorre a manutenção de todos os maquinários.

O presente trabalho constitui-se numa pesquisa exploratória - descritiva e delineia-se em três formas de investigação: bibliográfica, documental e estudo de caso. Por isso, após todo o levantamento bibliográfico e documental, a fase seguinte foi: a analise documental, a elaboração de um questionário programado e uma entrevista estrutura. Foram classificados seis tipos de custos ocultos para serem verificados sua possível existência na Agroindústria, que são: set-up, espera, ociosidade, acidente de trabalho, estoques e obsolescência. Tais escolhas são justificadas pela importância que ambos têm no cenário econômico das empresas.

Além dessas ferramentas, este trabalho incluiu também observações diretas através de visitas ao local de pesquisa, com o objetivo de verificar acontecimentos normais da empresa, registrando os eventos de forma organizada.

\section{Revisão Bibliografia}

Segue uma revisão teórica de conceitos originados nos campos de conhecimento requeridos pela teoria dos custos. Apresenta-se também uma breve revisão da Contabilidade de Custos, para que seja possível, enfim, atender ao propósito deste trabalho.

\subsection{Contextualização}

A Contabilidade de Custos foi criada e mantida por muito tempo com a finalidade básica de avaliação de estoques. Porém, há algumas décadas atrás, uma visão nova é tida a respeito da Contabilidade de Custos por parte dos usuários de custos, ou seja, a principio, a finalidade era à avaliação de estoques. Com o tempo, passou a ter outra finalidade, a de fornecer dados à Administração.

Com o desenvolvimento das empresas, surgiu a necessidade de se dispor de um instrumento eficiente capaz de atender aos aspectos de um novo cenário, no qual são necessárias certas 
adaptações quando se deseja desenvolver bem esse outro potencial voltado para o gerencial (MARTINS, 2003).

De acordo com Leone (1997) a Contabilidade de Custos deve atender a três objetivos básicos, que claramente têm aplicações possíveis, que são: determinar o lucro, controlar as operações e auxiliar na tomada de decisão.

Dessa forma, na determinação do lucro, são utilizados registros convencionais de contabilidade, isso para que os dados sejam tratados, de modo que se tornem mais úteis à administração. Quanto ao controle das operações, tudo ocorre em função do estabelecimento de padrões e orçamentos, comparação entre o custo real e o custo orçado e ainda previsões. A tomada de decisões fornece informações para o planejamento da direção, como é o caso, por exemplo: formação de preços, quantidade a ser produzida, que produto produzir e entre outros.

De modo geral, os objetivos são voltados para a empresa, isto é, a contribuir com os componentes organizacionais (administrativos e operacionais). Além do mais, não há uma quantidade determinada de objetivos na Contabilidade de Custos. Deste modo, estes serão fixados de acordo com as necessidades apresentadas pelos diversos setores gerenciais.

Observa-se que muitas empresas utilizam a Contabilidade de Custos para atender apenas às exigências fiscais, esquecendo-se ou não sabendo de que ela pode constituir-se em uma importante ferramenta de controle gerencial, fornecendo subsídios a diversos processos decisórios relevantes à administração.

A seguir, apresentar-se-á uma síntese conceitual da classificação dos custos.

\subsection{Classificação dos custos}

Existem diversas formas de se classificar os custos, dependendo da necessidade das informações a serem geradas a partir da observação destes. No entanto, em sua grande maioria, estes são o resultado da necessidade expressa pela gerência para ter uma visão sistêmica da organização, de modo que possa facilitar o seu processo decisório.

Para Martins (2003), Custo é um gasto relativo a bem ou serviço utilizado na produção de outros bens ou serviços. Sendo assim, o termo custo é um sacrifício incorrido para obter algum beneficio ou serviço previsto durante a atividade de produção. Por exemplo: salários de pessoal da produção, aluguéis e seguros do período da fabricação, entre outros.

Para se definir mais claramente as diversas formas de custos conhecidas e comumente utilizadas, é necessário um breve relato de sua classificação, (ver Tabela 1): 
Tabela 1 - Classificação dos custos

\begin{tabular}{|c|c|}
\hline Classificação & Consideração \\
\hline \multirow[b]{2}{*}{ De acordo com a diretibilidade } & $\begin{array}{l}\text { Custos Diretos - são aqueles que podem ser diretamente } \\
\text { apropriados a cada tipo de bem ou órgão, no momento da sua } \\
\text { ocorrência, isto é, estão ligados diretamente a cada tipo de } \\
\text { bem ou função de custo. (MARTINS, 2003). }\end{array}$ \\
\hline & $\begin{array}{l}\text { Custos Indiretos - são aqueles que não se pode apropriar } \\
\text { diretamente a cada tipo de bem ou função de custo no } \\
\text { momento da sua ocorrência. Atribui-se parcela deles a cada } \\
\text { tipo de bem ou função de custo através de um critério de } \\
\text { rateio. (SEVERIANO FILHO, 1999). }\end{array}$ \\
\hline \multirow[t]{2}{*}{ De acordo com a variabilidade } & $\begin{array}{l}\text { Custos Variáveis - são todos aqueles cujos valores se alteram em } \\
\text { função do volume de produção da empresa. Se não houver } \\
\text { quantidade produzida, o custo variável será nulo. Observa-se } \\
\text { que os custos variáveis devem ser analisados com respeito às } \\
\text { quantidades consumidas na produção e não às quantidades } \\
\text { adquiridas ou às estocadas. (LEONE, 1997). }\end{array}$ \\
\hline & $\begin{array}{l}\text { Custos Fixos - são aqueles cujos valores são os mesmos, qualquer } \\
\text { que seja o volume de produção da empresa, ou seja, } \\
\text { permanecem inalterados. (LEONE, 1997). }\end{array}$ \\
\hline \multirow[t]{2}{*}{ De acordo com a sua natureza } & $\begin{array}{l}\text { Custos tangíveis ou explícitos ou "mensuráveis" - são os que se } \\
\text { podem calcular com critérios convencionais de custos, em } \\
\text { muitos casos de acordo com princípios de contabilidade } \\
\text { geralmente aceites, e normalmente vão acompanhados de um } \\
\text { desembolso efetivo por parte da empresa" (AECA, 1995:). }\end{array}$ \\
\hline & $\begin{array}{l}\text { Custos intangíveis ou implícitos ou ocultos - é qualquer custo que } \\
\text { não seja aparente na contabilidade padrão, ou, em termos } \\
\text { gerais, que não esteja imediatamente aparente mas que seja } \\
\text { importante para o processo de produção. (FUREDY, 2005) }\end{array}$ \\
\hline
\end{tabular}

Fonte: Pesquisa direta (2005)

$\mathrm{O}$ aspecto da diretibilidade se encontra ligado a um determinado objeto de custo, ou seja, decorre da possibilidade de se atribuir um determinado item de custo a um determinado portador final ou objeto de custo. A segunda classificação diz respeito à variabilidade do item de custo também em relação ao comportamento de um determinado objeto de custo, mais precisamente com a variação ou diminuição do seu volume. Já a terceira classificação diz respeito á variabilidade do item de custo em relação à percepção de um determinado objeto de custo.

Após uma compreensão geral desse três critérios de classificação dos custos, a pesquisa foi focada apenas de acordo com a natureza, pois, é fonte de compreensão e desenvolvimento do raciocínio dos Custos Ocultos e resulta na base conceitual que sustenta a pesquisa. 


\subsubsection{De acordo com a sua natureza}

Custos tangíveis ou explícitos ou "mensuráveis" - São custos bem conhecidos e que podem ser estimadas de um modo bastante preciso, pois possuem valores quantificáveis. Por exemplo: vencimento de um funcionário, custo adicional de utilização de despesas, redução de taxas de erros e o aumento da capacidade de produção. Estes custos são passíveis de quantificação, podendo ser calculados de forma objetiva (AMAT, 1993). Debruça-se essencialmente sobre custos com defeitos, reprocessamento de produtos defeituosos, sanções, contingências por garantias, litígios, entre outros (LOBO, 1999).

Custos intangíveis ou implícitos ou ocultos - São os custos decorrentes de perdas que não podem ser calculadas com precisão (normalmente avaliadas por estimativa), pois possuem vantagens que não são facilmente quantificáveis (AECA, 1995).

De acordo com Lobo (1999, podem incluir-se nesta categoria de custos:

— Excessos de inventários;

- Custos de oportunidade de vendas perdidas devido a experiências negativas dos clientes ou devido à deficiente reputação da empresa;

- Saldos excessivos de contas devedoras;

- Desperdício em horas extras;

— Tempos não produtivos por erros de programação da produção;

- Tempo destinado a analisar as causas e conseqüências das falhas;

- Tempo consumido no tratamento das queixas.

Ao observa a filosofia dos Custos Ocultos, percebe-se um alto grau de dificuldade para mensurá-los, ainda que se compreenda claramente a sua existência, de modo que não podem ser diretamente associados a um produto ou processo. Além disso, os Custos Ocultos são diversos e superiores ao que é esperado pela maioria dos departamentos de contabilidade.

\subsection{Origem e definição dos Custos Ocultos}

A investigação dos Custos Ocultos é um fenômeno de interesse da sociedade moderna. Porém, a literatura é escassa, mas nada que iniba o empenho ou desejo pela área de conhecimento. Como se sabe há custos que dificilmente são detectados nos relatórios das organizações e que comprometem a lucratividade das empresas. No entanto, quando identificados, estimam valores, os quais agregam novas informações ao conjunto de dados que se tornam elementos adicionais do 
ponto de vista gerencial, pois fornecem informações que influenciam diretamente às perspectivas administrativa, de planejamento, controle e de investimentos.

A origem dos Custos Ocultos reside em uma interação complexa entre dois grupos de variáveis, ou seja, há uma interação permanente entre as estruturas da empresa e os comportamentos humanos, aqueles criados a partir do ortofuncionamento "funcionamento adequado" e dos disfuncionamentos "funcionamento inadequado" (SAVALL \& ZARDET, 1991).

Segundo Furedy (2005), "Custo Oculto é qualquer custo que não seja aparente na contabilidade padrão, ou, em termos gerais, que não esteja imediatamente aparente, mas que seja importante para o processo de produção".

De acordo com o traçado metodológico utilizado na pesquisa, são definidos em seis os números de Custos Ocultos estudados nesta pesquisa "set-up, espera, ociosidade, acidente de trabalho, estoques e obsolescência”.

Os custos relacionados ao set-up estão ligados às falhas e ao mau uso do tempo de preparação do processo produtivo; a espera seria ocasionada por procedimentos e métodos não ligados àqueles já dimensionados dentro do processo, como demonstrado nos fluxos e mapofluxogramas da produção; ociosidade refere-se ao não funcionamento no tempo certo e determinado do processo produtivo; os acidentes de trabalho são custos que deveriam ser evitados com a prevenção e não uso de procedimentos que os provocam; os estoques provocam altos custos quando mau administrados, gerando custos de manutenção e acondicionamento, levando a entidade a "empatar" o capital circulante líquido (capital de giro) e a obsolescência é o ato ou efeito de determinados fatores ou funções da manufatura tornarem-se ineficazes e ineficientes para agregação de valor ao produto.

\subsubsection{Elementos de Custos Ocultos}

Segundo Lima (1991), os elementos de Custos Ocultos podem ser classificados e decompostos como a seguir:

- Elementos de custo de absenteísmo

- Elementos de custos de acidente de trabalho

- Elementos de custos de rotação de pessoal

- $\mathrm{O}$ custo de não qualidade

- Os custos ligados à produtividade direta

É notório que as empresas convivam com algumas dessas situações ou circunstâncias, por isso que nos últimos tempos passou-se a ter como foco centrado os custos indiretos, pois são custos 
que dificilmente são precisos e, com isso, proporcionam um ambiente inseguro quando se trata dos reais custos da produção industrial.

Observa-se que, algumas empresas têm almejado a mensuração dos Custos Ocultos como forma de garantir sua competitividade futura, para evitar custos desnecessários. Assim, os Custos Ocultos serviriam de direcionadores de ações gerenciais, pois, é de fundamental importância conhecer todos os custos industriais.

Até este ponto, a revisão bibliográfica criou condições para conduzir uma linha de raciocínio onde as informações são direcionadas para a compreensão da ideologia dos Custos Ocultos . Na seção seguinte é apresentada a aplicabilidade da teoria através dos recursos metodológicos utilizadas para atender ao objetivo da pesquisa.

\section{Contextualização do estudo}

A pesquisa foi realizada no período de novembro a dezembro de 2005, em uma Agroindústria, cujo foco principal é a fabricação de álcool, que está sediada no município de Pedras de Fogo, no Estado da Paraíba. O início das atividades da organização ocorreu em 1971, sendo a primeira destilaria autônoma do Brasil.

Após um período de observação e análise da realidade vivenciada na empresa, puderam ser detectados alguns Custos Ocultos. Inicialmente, convém salientar que a um aspecto facilitador para o gerenciamento dos custos da entidade, é o fato de que o mix de produtos produzidos é restrito a quatro tipos de álcool (hidratado, neutro, anidro e o envelhecido). No entanto, existem alguns desses que são matérias-primas para a fabricação dos demais. Por exemplo: o álcool hidratado é base para a produção do álcool neutro e do anidro.

Por outro lado, constatou-se que a Agroindústria possui um porte elevado quanto à estrutura, o que representa um custo elevado de capital investido; Visto que, a Agroindústria entra em pleno funcionamento no período de safra, o que representa seis meses do ano e, os outros seis meses, representam o estado de manutenção das máquinas.

O processo produtivo da Agroindústria possui sete etapas “setores"; (1). balança "pesagem da matéria-prima”, (2). sacarose, (3). moagem, (4). fermentação, (5). destilação, (6). armazenagem e (7). expedição. A pesquisa foi efetivamente aplicada nos setores de moagem, fermentação e destilação, em função de serem as operações mais complexas e por possuírem a maior concentração de recursos (máquinas e mão-de-obra direta).

Tais procedimentos são comentados nos próximos tópicos. 


\subsection{Coleta de dados e informações}

Esta seção apresenta os resultados do estudo, de cuja análise e interpretação obteve-se a verificação dos Custos Ocultos na Agroindústria.

Para solucionar ou atender ao objetivo da pesquisa, foi proposto uma entrevista semiestruturada com uma relação contendo uma lista de seis possíveis Custos Ocultos.

Os Custos Ocultos foram levantados de acordo com observações diretas mediante a aplicação da entrevista semi-estruturada. A seguir são apresentados esses custos :

Tabela 2 - Os Custos Ocultos

\section{Custos Ocultos}

\begin{tabular}{l|c|c|c|c|c|c}
\hline Setores & Set-up & Espera & Ociosidade & $\begin{array}{c}\text { Acidente } \\
\text { de } \\
\text { Trabalho }\end{array}$ & Estoques & Obsolescência \\
\hline Moagem & Não & Não & Sim & Sim & Sim & Não \\
\hline Fermentação & Não & Não & Sim & Sim & Sim & Não \\
\hline Destilação & Não & Não & Sim & Sim & Sim & Não \\
\hline
\end{tabular}

Fonte: Pesquisa direta (2005)

Após a matéria-prima ter passado pelos setores de Balança e Análise (Laboratório de Sacarose), em seguida segue para etapa de moagem.

Antes de tecer qual quer consideração, vale salientar que, ao fazer um corte temporal, ter-seá dois momentos distintos: um durante o período de safra e outro durante o período de entre safra. Por isso se têm analises temporais em função da realidade momentânea vivida pela Agroindústria. Percebe-se que não foram constatadas as seis categorias de Custos Ocultos, mas isso não significa que não existam outros intangíveis, ou mesmo que esses custos não existam de fato.

Quando tratamos do Set-up percebemos em sua totalidade que não foi detectado sua presença nos setores de moagem, fermentação e destilação. Isso é justificado pelo fato de que as máquinas são preparadas para o inicio do processo (início da safra) e só param quando finalizam o processo produtivo (entre safra).

Da mesma forma, a Espera em sua totalidade não foi detectada, visto que a produção é continua e existe uma grande sincronia entre a fabricação e a demanda. 
No caso especifico da Ociosidade, ocorrerá de fato no momento de entre safra, pois, as máquinas representam um capital muito alto para a Agroindústria, ou seja, há um grande capital sem rotação.

O item Acidente de trabalho envolve um alto Custo Oculto, pois requer um tratamento especifico para cada circunstância, e, além do mais, o fato de um funcionário ter que substituir outro representa um custo em dobro.

Como a Agroindústria trabalha com o sistema de produção continua não haverá Estoque durante o processo produtivo, mas foi observado que a Agroindústria estoca seu produto acabado e o mesmo representa um grande custo, pois é feito um planejamento para que o álcool produzido possa abastecer a demanda durante o período de entre safra.

A Obsolescência não foi identificada. As máquinas e equipamentos estão em boa conservação, visto que a Agroindústria utiliza-se da manutenção preventiva.

\section{Considerações Finais}

A experiência de realização deste estudo sugere algumas considerações finais, as quais apontam para as circunstâncias comportamentais em que foram identificados os Custos Ocultos na empresa estudada. Das seis categorias de custos rastreadas, pelo menos $50 \%$ destes foram identificados, em grau e relevância não examinados, em função do traçado metodológico utilizado na pesquisa. Esta observação indica a necessidade de uma ampliação deste estudo, com vistas a um mapeamento mais completo dos Custos Ocultos, bem como seus indicadores de grau e relevância.

Os Custos Ocultos identificados na pesquisa estão todos relacionados com disfuncionamentos organizacionais inerentes à estrutura da empresa pesquisada. Esta constatação sugere uma revisão do modelo organizacional adotado pela entidade, na perspectiva de redução e/ou mesmo, a eliminação destes custos.

Finalmente, percebe-se que a Contabilidade de Custos e mesmo os Sistemas de Controladoria estão longe de atenderem aos procedimentos de identificação, operação e medição dos Custos Ocultos. Este fato aponta para a necessidade de uma aceleração da pesquisa no campo da Contabilidade, mediante o incremento de esforços voltados ao seu aperfeiçoamento e avanço.

Este incremento diz respeito à possibilidade de reconhecimento, apuração e mensuração dos custos ocultos. Tais funções podem ser alcançadas através do aperfeiçoamento e avanço dos estudos ligados aos sistemas de custeio, bem como às conseqüências que esses custos trazem para a aferição de desempenho e o desenvolvimento da empresa como um todo, tendo em vista que os custos ocultos estão ligados não somente ao processo, mas também às pessoas envolvidas nele. 


\begin{abstract}
The technological progresses and the constants changes that are happening in the world economy scenery also contemplate in needs of changes in the accounting. In this context, it is noticed that there is a need to perfect the accounting procedures so that they come to contemplate the accountancy of the Occult Costs. The present article deals with a research that tried to identify the present Occult Costs in an Agriculture-industry, " Distillery of alcohol ". It is pointed out that the result of this research is the practical and technical fundamentals on the study of the Occult Costs. Initially it is presented the scope and evolution of the Accounting of Costs, culminating with the classification and origin of the Occult Costs. Later there are raised the possible Occult Costs present in the Distillery of alcohol.
\end{abstract}

Key-words: occult costs; cost accounting; costs.

\title{
Referências
}

AECA (Asociacion Española de Contabilidad y Administracion de Empresas). Costes de Calidad, Principios de Contabilidad de Gestion, Ediciones Gráficas Ortega, Madrid, 1995.

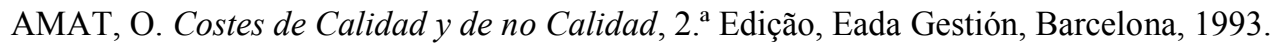

FUREDY, Christine. Revista de Agricultura Urbana. Acesso em: 01 nov. 2005. Disponível em: http://www.agriculturaurbana.org.br/RAU/AU6/AU6residuos.html

LEONE, George Sebastião Guerra. Curso de Contabilidade de Custos. Editora Atlas, São Paulo, 1997.

LIMA, M. A. A. A estrutura e as ferramentas da intervenção-pesquisa sócio-economica nas empresas e demais organizações. Revista de Administração de Empresas. São Paulo, p.21-30, jan./mar.,1991.

LOBO, C. O Tratamento Contabilístico dos Custos da Qualidade - Estudos de Casos em Empresas Portuguesas. Dissertação de Mestrado em Contabilidade e Auditoria. Universidade do Minho, Braga, 1999.

MARTINS, Eliseu. Contabilidade de custos. São Paulo: Atlas, 2003.

MEGLIORINI, Evandir. Custos. São Paulo: MAKRON Books, 2001.

SAVAL, Henri e ZARDET, Véronique. Maitriser lês coúts et les performances cachês. Paris: ed. Economica. Caps. 3 a $5,1991$.

SEVERIANO FILHO, Cosmo. Custo Industrial. João Pessoa. UFPB/DEP/CT apostila, 1999. 


\section{Dados dos autores}

Nome completo: João Batista de Freitas

Filiação institucional: Universidade Federal da Paraíba

Departamento: Engenharia de Produção

Endereço: Rua: Elvira C. da Silva, 21, apto. 303, Bancários, João Pessoa, Brasil, CEP: 58052-190.

Telefone: (83) 8803-4065

e-mail: joaosousa@oi.com.br

Nome completo: Cosmo Severiano Filho

Filiação institucional: Universidade Federal da Paraíba

Departamento: Engenharia de Produção

Função ou cargo ocupado: Professor Associado I

Rua: Ana Maria Barbosa de Almeida, 306, Edifício Atlantis , apto. 402, Bancários, João Pessoa, Brasil, CEP: 58052-270

Telefone: (83)3043-6801

e-mail: cosmosf@ufpb.ct.br

Recebido para publicação em: 25/10/2006

Aceito para publicação em: 02/02/2007 